\title{
Effects of Oyster Mushroom Pleurotus pulmonarius on Preparasitic Larvae of Bovine Trichostrongyles
}

A wide range of fungi which feed on nematodes occur in the soil and various decaying organic materials. Collectively they are designated nematode-destroying fungi, and they have developed different sophisticated strategies for infecting or capturing their prey. The ability of these fungi to destroy nematodes has shown not only to be limited to the free-living nematodes, but many of them may as well affect nematodes parasitic to crop plants and domestic animals.

Recently, Thorn \& Barron (1984) reported that fungi belonging to the genus Pleurotus, the edible oyster mushroom, were capable of destroying soil-dwelling rhabditoid nematodes. It has been shown that when nematodes come in contract with small droplets on the hyphae of the fungus, they become immobilized very quickly due to a nematotoxin, and are subsequently colonized and digested by the fungus (Barron \& Thorn 1987). In addition, the oyster mushroom may develop adhesive knobs on its mycelium as trapping organs for the nematodes (Saikawa \& Wada 1986). The present study was designed to examine whether this mushroom could destroy the preparasitic stages of 2 common trichostrongyles of cattle, Ostertagia ostertagi and Cooperia oncophora.

Larvae of the 2 trichostrongyle species were obtained by culturing faeces collected from calves with experimental monospecific infections. Baermann extraction of the cultures after short and long incubation periods allowed isolation of batches of preinfective (1st and 2nd stage) and infective (3rd stage) larvae, respectively. The fungus Pleurotus pulmonarius (Somycel 3014) was grown on 1:40 corn meal agar in small petri dishes (diameter $4 \mathrm{~cm}$ ). Approximately 500 larvae of the respective larval categories were added in 2 drops of water to the agar surface of petri dishes with and without P. pulmonarius. Numbers of mobile larvae were enumerated under the stereomicroscope at 4 and 8 $h$ after adding the larvae. On each occasion 100 larvae were registered as a minimum per dish. The number of mobile individuals on a fungus dish was expressed as a percentage of that of a corresponding fungus-free control dish.

Table 1 shows that preinfective larvae of both trichostrongyle species were markedly influenced by exposure to the fungus. At $4 \mathrm{~h}$ few or none mobile larvae were noticed and at $8 \mathrm{~h}$ mobile individuals were no longer observable. Immobilized larvae were widely distributed on the agar surface of the fungus dishes and in some larvae hyphae were seen.

Table 1. Percentage of mobile larvae of Ostertagia ostertagi and Cooperia oncophora, exposed to Pleurotus pulmonarius.

\begin{tabular}{|c|c|c|c|c|}
\hline \multirow[b]{2}{*}{$\begin{array}{l}\text { Exposure } \\
\text { time } \\
\text { (h) }\end{array}$} & \multicolumn{2}{|c|}{ O. ostertagi } & \multicolumn{2}{|c|}{ C. oncophora } \\
\hline & $\begin{array}{c}\text { Pre- } \\
\text { infective } \\
\text { larvae }\end{array}$ & $\begin{array}{c}\text { Infective } \\
\text { larvae }\end{array}$ & $\begin{array}{c}\text { Pre- } \\
\text { infective } \\
\text { larvae }\end{array}$ & $\begin{array}{c}\text { Infective } \\
\text { larvae }\end{array}$ \\
\hline 0 & 100 & 100 & 100 & 100 \\
\hline 4 & 0 & 66 & 7 & 100 \\
\hline 8 & 0 & n.d. & 0 & n.d. \\
\hline
\end{tabular}

n.d.: not determined. 
In control dishes normal larval mobility was maintained throughout. Table 1 also shows that infective larvae of $\boldsymbol{O}$. ostertagi were affected to a certain degree whereas those of $C$. oncophora were not influenced at all by fungal exposure. After $4 \mathrm{~h}$ the infective larvae accumulated at the periphery of the dishes. This larval behaviour rendered the enumeration after $8 \mathrm{~h}$ impossible.

The results show that $P$. pulmonarius may exert a strong immobilizing effect on preinfective larvae of $O$. ostertagi and $C$. oncophora, whereas there seemed to be little or no effect on infective stages of these species. This difference may perhaps be explained by a protective role of the outer cuticle of the latter larvae. Thorn \& Barron (1984) and Barron \& Thorn (1987) showed that some few immobilized individuals of rhabditoid nematodes regained normal mobility when removed from fungus dishes. These and other questions related to Pleurotus spp. and larvae of animal parasitic nematodes will be investigated in future experiments.

\section{Acknowledgements}

The authors wish to thank Dr. Kaj Beck, Royal Veterinary and Agricultural University, for providing the fungal cultures. Dr. Henrik Bjørn, Royal Veterinary and Agricultural University, Dr. S. Aa. Henriksen, National Veterinary Laboratory, and Dr. E. Wedø, State Serum Institute, are all thanked for maintenance and supplying of nematode material.

Michael Larsen \& Peter Nansen,

Dept. of Veterinary Microbiology,

Royal Veterinary and Agricultural University, Frederiksberg C, Denmark.

\section{References}

Barron $G L$, Thorn $R G$ : Destruction of nematodes by species of Pleurotus. Can. J. Bot. 1987, 65, 774-778.

Saikawa M, Wada N: Adhesive knobs in Pleurotus ostreatus (the oyster mushroom), as trapping organs for nematodes. Trans. mycol. Soc. Japan 1986, 27, 113-118.

Thorn RG, Barron GL: Carnivorous mushrooms. Science 1984, 224, 76-78.

(Received July 30, 1990; accepted October 18, 1990).

Reprints may be requested from: Michael Larsen, Department of Veterinary Microbiology, Royal Veterinary and Agricultural University, 13 Bülowsvej, DK-1870 Frederiksberg C, Denmark. 